\title{
THE TENTH CANADIAN HIGH POLYMER FORUM
}

$\mathrm{O}^{\mathrm{N}}$ September 7, some 170 scientists drawn mainly from Canada and the United States began a two and a half day conference on natural and synthetic macromolecules, under the general ehairmanship of Dr. L. A. McLeod. As Dr. Sivertz reminded the conference, the study of high polymers in Canada, which was already important in relation to the large pulp and paper industry, received further impetus when, in 1942, Canada became a joint partner with the United States in the manufacture of synthetic rubber. A small working party drawn from the universities and industry was then set up, and from this developed open conferences and finally the Canadian High Polymer Forum was constituted and held its first meeting in 1949. Since that date meetings have been held at almost yearly intervals, and these have been characterized by informal and intimate discussion of contributed papers on a variety of topics. The meeting reported on here was the tenth in the series, and among other activities was marked by a banquet at which the mood of the principal speakers combined reminiscence with planning for the future.

Perhaps an outsider may be permitted to say that the meetings have not only served their regional and national purpose with particular success but have also been of wider value and importance, and that it is therefore entirely appropriate that the Canadian High Polymer Forum should be host to the International Symposium on Macromolecular Chemistry at Montreal on July 27-August 1, 1961. The relative merits of the small discussion group and the large conference with unrestricted membership have often been argued ${ }^{1}$ and it will not be surprising if on the basis of its experience of earlier forums the organizing committee attempts to preserve the advantages of the former at the Montreal meeting. The eleventh Forum will not be held until the autumn of 1962 or the spring of 1963 .

Twenty-four papers, all of which cannot be mentioned here, were presented at the tenth Forum. Five of these were concerned with ionic polymerization of unsaturated hydrocarbons. From these it appeared that rate constants for some of the individual steps in both cationic and anionic polymerization are now becoming available and it should not be long before coherent kinetic and mechanistic patterns emerge. Thus Dr. P. H. Plesch gave a value for $k_{p}$ for the titanium chloride catalysed polymerization of isobutene in methylene chloride at $-60^{\circ} \mathrm{C}$. and values of the Arrhenius parameters of the spontaneous termination, monomer transfer and water transfer reactions relative to those for the propagation reaction, from which it appeared that monomer transfer is the last chain-breaking reaction to survive at low temperatures. Dr. A. M. Eastham gave an account of interesting attempts to study the initiation reaction free from the complications of propagation by an investigation of the kinetics of the geometrical isomerization of but-2-ene in ethylene dichloride induced by boron trifluoride-methanol mixtures. The results seem to show rather surprisingly that an adduct of but-2-ene, methanol and two molecules of boron trifluoride may be involved. In a rare, but most welcome, contribution from one of the pioneers (R. M. Thomas) of cationic polymerization three new important findings were reported. The first was a medium for achieving liquid-phase cationic polymerization of isobutene at - $185^{\circ}$, the second the demonstration by carbon-14 tracer techniques of solvent-fragment incorporation in the polymer and the third was the existence of an 'inversion' temperature of about $-45^{\circ}$, above which the degree of polymerization of polyisobutene produced by aluminium chloride catalysis increases with monomer concentration and below which it decreases. This last result provoked much discussion, and mechanisms of chain termination involving two monomer molecules were advanced. Prof. M. Szwarc described a capillary flow method involving contact times in the range $0 \cdot 2-1 \cdot 5$ sec. for measuring the $k_{p}$ for anionic polymerization of styrene in tetrahydrofuran solution with $\mathrm{Na}^{+}$as the counter ion, and also the preliminary results obtained, together with the relative efficiency of water and methyl iodide as chain terminators. An elegant spectrophotometric method for measuring the relatively slow reaction of lithium butyl with styrene was described by Drs. S. Bywater and D. J. Worsfold. The definite but unexpected result was obtained that, contrary to earlier work, the rate of the initiation reaction is proportional to [styrene] ${ }^{1.0}$ $[\mathrm{Li} \mathrm{Bu}]^{0.15}$, whereas the rate of propagation is proportional to [styrene] ${ }^{1.0}\left[\mathrm{Bu} \text { (styrene) }{ }_{n}^{-} \mathrm{Li}^{+}\right]^{0.5}$. It seems that a six-fold aggregate of lithium butyl and bimolecular association of growing $\mathrm{Bu}$ (styrene) ${ }_{n}^{-} \mathrm{Li}^{+}$ ion pairs must be involved in reactions in the lithium butyl catalysed polymerization of styrene. The latter association was much discussed in relation to earlier and later contributions (especially that of N. Nikolov) and generally agreed to be important in more concentrated solutions.

Free-radical processes received due measure of attention particularly in relation to unusual phenomena in solid systems. Thus the effect of sulphurcontaining antioxidants is promoted not only by carbon black but also by polyacenes, diphenylpolyenes and substances capable of generating quinonoid structures. The effect was ascribed by the Bell Telephone Laboratory workers to formation of $\pi$-bond complexes between the promoter as acceptor and thiyl radicals as donors, thereby reducing the reactivity of the latter as hydrogen abstracting agents. Dr. R. J. Ceresa showed that the kinetics of the swelling of chemically cross-linked or molecularly entangled polymers by vapours followed similar courses, showing discontinuities to be associated with mechanical rupture of chains or the cross-links since the use of vinyl monomers as swelling agents leads to the formation of block copolymers. The hitherto somewhat puzzling phenomena connected with the polymerization of vinyl monomers in aqueous solution were discussed, and shown to be approaching rational codification based on the mutual compatibilities and the water solubilities of monomer and polymer, and the susceptibility of soluble polyradicals to oxidative and reductive termination by ions of metals of variable valency. The rate constants of the growth and termination processes of the soluble 
radicals are not too dissimilar from those in nonaqueous media and are quite independent of those of any longer-lived radicals in suspended polymer particles.

Full characterization of a solution of a polymer requires a knowledge of the structure, sizes and shapes of all the polymer molecules present and of its equili. brium properties as manifested in partial molal values of thermodynamic functions of solvent and solute. Many of the papers were concerned with this topic in one or other form. One, by Drs. W. H. Beattie and J. T. Bailey, was a timely cautionary reminder, generally acknowledged, of the need for a sharpening of our perception of the significance of the number, weight, $Z$ and $Z+1$ averages obtained from light scattering. Another, by Dr. W. Cooper and his associates of the Dunlop Rubber Co., Ltd., showed that second-order virial coefficients obtained from light scattering measurements on polybutadiene are strongly dependent on chain branching and revealed that the branch points are preferentially susceptible to mechanical breakdown. One of the most exciting contributions was that in which Prof. W. Heller of Wayne State University described his attempts to "walk around" macromolecular particles oriented in a streaming solution by observing the light which they scatter when illuminated from chosen directions. Already this fascinating but technically very difficult approach has not only indicated the shape of rigid particles but has also given insight into molecular elasticity by providing indications of the change of shape of flexible coiled macromolecules under the influence of shearing forces. If this method could possibly be extended to the use of polarized light an immensely powerful tool would become available. A further paper on polymer solutions by Dr. B. E. Conway dealt with the thermodynamics of the polar system polyoxypropylene glycol in methanol. The decrease in hydroxyl content with increase in molecular weight of the polyoxypropylene glycol leads to a change of sign in the heat of mixing; the experimental entropies and free energies of mixing can be accounted for by the Münster theory, which takes into account specific solvent orientation effects.

A number of the authors described the application of new experimental techniques to the solution of polymer problems. Dr. L. A. MeLeod has fractionated elastomers such as cis-1,4-polybutadiene using elution chromatography, and Dr. Bacon $\mathrm{Ke}$ showed that differential thermal analysis is not only useful in determining transition temperatures and heats of fusion of simple polyamides but may also give information concerning the structures of copolymers. Dr. W. Prins described a versatile osmometer which is capable, among other things, of measuring the de-swelling of polyelectrolyte gels. In this application the gel and solvent are saparated by a porous stainless steel disk of porosity $5-65 \mu$, and the change in gel volume is measured when pressures of up to 200 atmospheres are applied to the gel phase.

Some interesting developments in the field of new polymers and copolymers were described. The strong and highly extensible elastomers produced by the incorporation of 2,4-toluene diamine in copolymers of polyoxypropylene glycol and 2,4-toluene diiso. cyanate were discussed by A. J. Havlik of the California Institute of Technology. Poly (5-methyl, 3-vinyl, oxazolidine-2-one), of which the surprising properties in water were reported by W. E. Walles at the ninth Forum, forms strong complexes with a wide variety of organic compounds. The complex with phenol in which one phenol molecule may be bound per monomer unit in the polymer owes its strength to hydrogen bonding, but more unusual are the fairly strong complexes of the polyoxazolidinone with methyl bromide and bromine.

It is a tradition of these meetings to have a guest speaker who delivers the Conference lecture. This year the speaker was Prof. F. S. Dainton and his topic was "Why Polymerization Occurs". The central theme was that addition polymerization, which is usually regarded only from the point of view of the kineticist, is merely the aggregation of freely translating monomer molecules into larger molecules in which the basic units are joined by primary chemical valencies. Except in the nature and strength of the inter-unit linkage it is thus entirely analogous to physical aggregation processes such as condensation and crystallization and like these can be examined thermodynamically. The now familiar ${ }^{2}$ notions of 'ceiling' and 'floor' temperatures, monomer-polymer equilibria and metastability phenomena were treated by the lecturer in relation to a wide range of systems. Recent calorimetric values of heats of polymerization and the entropies of polymers were used to illustrate the large effects on the heats and the minor effects on the entropies of polymerization of certain structural groupings in the monomer.

F. S. DAINTON

K. E. Russeli

${ }^{1}$ Nature, 184, 835 (1959) ; 186, 283 (1960).

'See Dainton, F. S., and Ivin, K. J., Quart. Rev., 12, 61 (1958).

\section{PHILOSOPHY OFBSCIENCE}

$\mathrm{T}$ WE British Society for the Philosophy of Science held its fifth annual conference at Wills Hall, University of Bristol, during September 23-25. The four formal meetings and discussions, organized by Dr. Mary Hesse (Cambridge), were attended by fifty members and guests.

At the first meeting, with Prof. H. Heilbronn (Bristol) in the chair, two papers on the relation between pure and applied mathematics were read. Accepting the views of Frege, Cantor and others that the concepts of pure mathematics are exact, and of
Waismann and others that empirical concepts are inexact, Prof. S. Körner (Bristol) introduced a new generalized logic which embraced relations not only between exact concepts but also between inexact concepts and between exact and inexact concepts. He showed that 'purely exact' and 'internally inexact' concepts, as he defined them, could be identified with pure mathematical and empirical concepts respectively, and that they were logically unconnected. $\mathrm{He}$ thus described the application of mathematics as a threefold process : inexact empirical concepts are 